\title{
Capturing the spatiotemporal variability of fine particulates in travel microenvironments using GPS technology
}

\author{
S. P. Greaves \\ Institute of Transport and Logistics Studies, \\ University of Sydney, Australia
}

\begin{abstract}
While it is an area of ongoing epidemiological debate, evidence is growing that repeated short-term exposures to elevated levels of fine airborne particulate matter $\left(\mathrm{PM}_{2.5}\right)$ are a serious public health concern. Transport microenvironments have received particular scrutiny both because of the higher levels of fine particulates associated with road traffic and the fact people spend a significant amount of time traveling (for instance, 80 minutes/day for residents of Sydney). While several small-scale studies have been completed recently to establish the main factors impacting $\mathrm{PM}_{2.5}$ exposure, available measurement methods restrict sampling to coarse intervals such as every 30 minutes or by trip. While this provides an indication of total exposure across the sampling interval, it is not able to provide data at the level of time-resolution required to identify peak excursions in $\mathrm{PM}_{2.5}$ within a journey or associate this with specific elements of that journey such as traveling through a tunnel, idling in heavy traffic, or traveling behind a diesel truck. With this in mind, the current paper reports on a recent study in which the capabilities of a personal Global Positioning System (GPS) device and portable aerosol monitor are combined to collect these data on a variety of transportation modes in Sydney. This ability to easily collect, report and analyse pollution data at a highly disaggregate temporal and spatial level provides a flexible and powerful tool for identifying intra-trip variability in pollution levels as well as the location and magnitude of peak exposures of $\mathrm{PM}_{2.5}$.
\end{abstract}

Keywords: GPS, personal exposure, fine particulates, travel microenvironments. 


\section{Introduction}

The connection between exposure to airborne particulate matter (PM) and adverse health consequences is a topic of hot debate [1]. Of particular focus recently have been the finer fractions, particularly those with an aerodynamic diameter of less the 2.5 microns $\left(\mathrm{PM}_{2.5}\right)$, because of their deeper penetration into the gas exchange region of the lung. While current standards refer to maximum concentrations not to be exceeded over one day and possibly one year, recent epidemiological evidence suggests peak exposures of one hour or less may be more relevant from a health perspective $[2,3]$. The implications are that it is critical to know with greater precision the microenvironments in which higher levels of particulate concentrations occur and how long individuals spend in these microenvironments as they go about their daily business.

Transport microenvironments have come under particular scrutiny, both because concentrations of $\mathrm{PM}_{2.5}$ are consistently higher than ambient readings from fixed site pollution monitors and people spend a significant amount of time within such environments, whether as motorists, bus passengers, cyclists or walkers [4]. In response, several experimental studies have been conducted to identify the factors impacting exposure to $\mathrm{PM}_{2.5}$ while travelling (e.g., [5-10]). While direct comparisons between these studies are hampered by the use of different collection methods, $\mathrm{PM}_{2.5}$ is clearly influenced by a number of factors pertaining to the surrounding traffic (volumes, mix, fuel quality), the mode of travel, the in-vehicle environment of the vehicle, and meteorological conditions such as relative humidity and wind speed.

A review of the various studies, also suggests that much of the intra-trip variability in $\mathrm{PM}_{2.5}$ goes unexplained. This is because, the gravimetric measurement methods used, while highly accurate, restrict analyses to a coarse sampling interval such as a trip of reasonable duration (note, while it is highly variable, the suggestion in the literature is that at least 60 minutes is required to capture sufficient $\mathrm{PM}_{2.5}$ for a meaningful gravimetric analysis). This does not permit the identification of both the location and magnitude of peak excursions in $\mathrm{PM}_{2.5}$ within a journey or associate this with specific elements of that journey such as traveling through a tunnel, idling in heavy traffic, or traveling behind a diesel truck or bus.

With these issues in mind, the current paper reports on a recent study in which the capabilities of a personal Global Positioning System (GPS) device and a portable particle monitor are combined to collect spatially referenced $\mathrm{PM}_{2.5}$ data while traveling by various modes of transport in Sydney. This ability to easily collect, report and analyse pollution data at a highly disaggregate temporal and spatial level provides a flexible and powerful tool for identifying intra-trip variability in pollution levels as well as the location and magnitude of peak exposures of $\mathrm{PM}_{2.5}$. 


\section{Experimental set-up}

The experimental set-up used to collect and record $\mathrm{PM}_{2.5}$ at high levels of spatial and temporal resolution comprises the Neve personal GPS data logger (Figure 1) and the AM510 SidePak $^{\mathrm{TM}}$ personal aerosol monitor, manufactured by TSI Inc (Figure 2). The Neve device has been the culmination of 18 months of collaboration between our group and an Australian manufacturer [11]. In addition to possessing all the known advantages of GPS (accurate capture of location, time, velocity, and heading information, easily viewable within a Geographic Information System (GIS) etc), the device only weighs 103 grams, can store data for several weeks, and can be attached to a key-ring or clipped to a belt. It is therefore highly conducive to collecting personal travel information on all modes with little respondent burden.

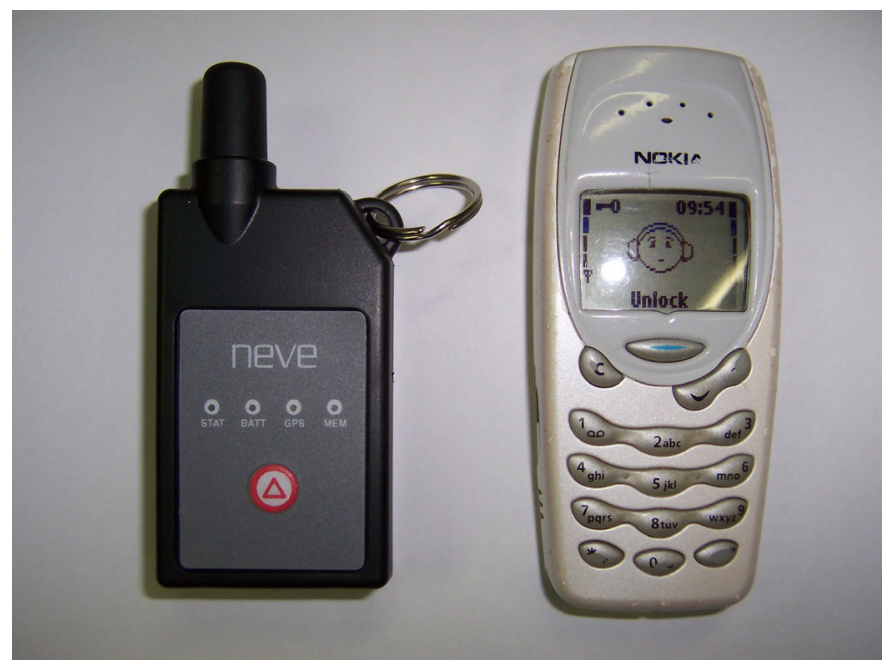

Figure 1: $\quad$ New Personal GPS device compared to mobile telephone.

The AM510 SidePak ${ }^{\mathrm{TM}}$ personal aerosol monitor provides second-by-second concentrations of $\mathrm{PM}_{2.5}$. The device uses nephelometric (light-scattering) techniques, which provide an estimate of particle mass through calibration against the aerosol of interest. The device is factory calibrated to the respirable fraction of ISO test dust, which allows for detection of most aerosols of importance in personal exposure to particulates (ISO Fine Test Dust, 12103-1, A2; Powder Technology Inc., Burnsville, MN). While this is standard practice for nephelometers, empirical evidence suggests results in roadway environments may be higher than gravimetric measures, particularly at higher concentrations $[3,12]$. This is a factor of the light-scattering properties of different particles. The intuitive answer is to run side-by-side comparisons with gravimetric methods. However, this is problematic, because results are affected by climatic conditions, particularly relative humidity, and errors in gravimetric 
measurements due to volatilisation of semi-volatile materials and chemical reactions of gases with collected particles [13]. For these reasons, it was deemed appropriate to report and analyse the results directly from the device with the caveat that the results should be used as an indication of those instances on a trip requiring further scrutiny.

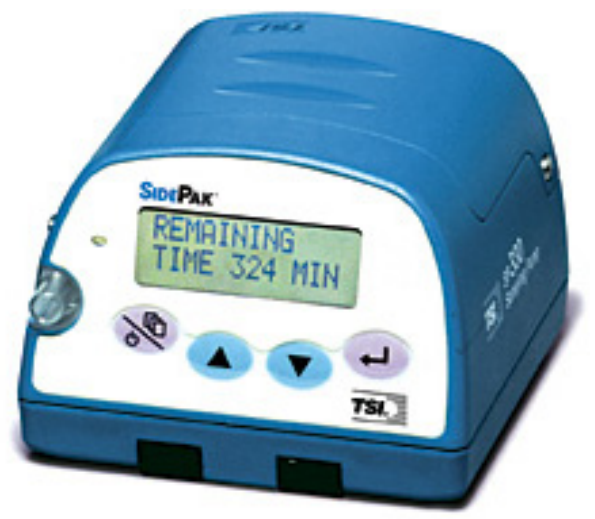

Figure 2: $\quad$ The AM510 Sidepak $^{\mathrm{TM}}$ personal aerosol monitor.

\section{Empirical testing and analysis}

The combined GPS/Aerosol monitor approach has (and continues to be used) to collect data while travelling by car, train, bus, bicycle, and walking in a variety of street environments in Sydney. While the method has provided great insight into local variations in $\mathrm{PM}_{2.5}$, there are issues to be aware of in the set-up and particularly the subsequent data processing. First, it is critical the Sidepak is time-synchronised to the GPS time, which it should be noted is 14 seconds ahead of standard UTC time (see http://www.leapsecond.com/java/gpsclock.htm). Second, following data download, software routines are needed to reformat the GPS data and match the particulate readings - the issue here is the GPS data are not always reliable due to signal loss and degradation resulting from overhead obstacles and urban canyon effects. Third, GPS data points need to be checked and imputed within the GIS environment based on adjacent points and the underlying network to create a more complete data set. While much of this can be automated through intelligent scripting routines, there is still a need for manual checking of results.

\subsection{Car trips}

Data have been collected for several car commute trips for colleagues travelling to the university. Several GIS plots and time-series graphs of the $\mathrm{PM}_{2.5}$ concentrations have been prepared such as that shown in Figure 3, which represents a $30 \mathrm{~km}$ trip from the Western suburbs of Sydney. In terms of the 
insights provided, it is immediately clear that the use of a trip-based average is hiding the fact there is considerable variability in concentrations across the trip. It is also evident that levels tend to be worse in the more heavily-trafficked, stopand-go sections, with several large spikes/hotspots throughout the trip.
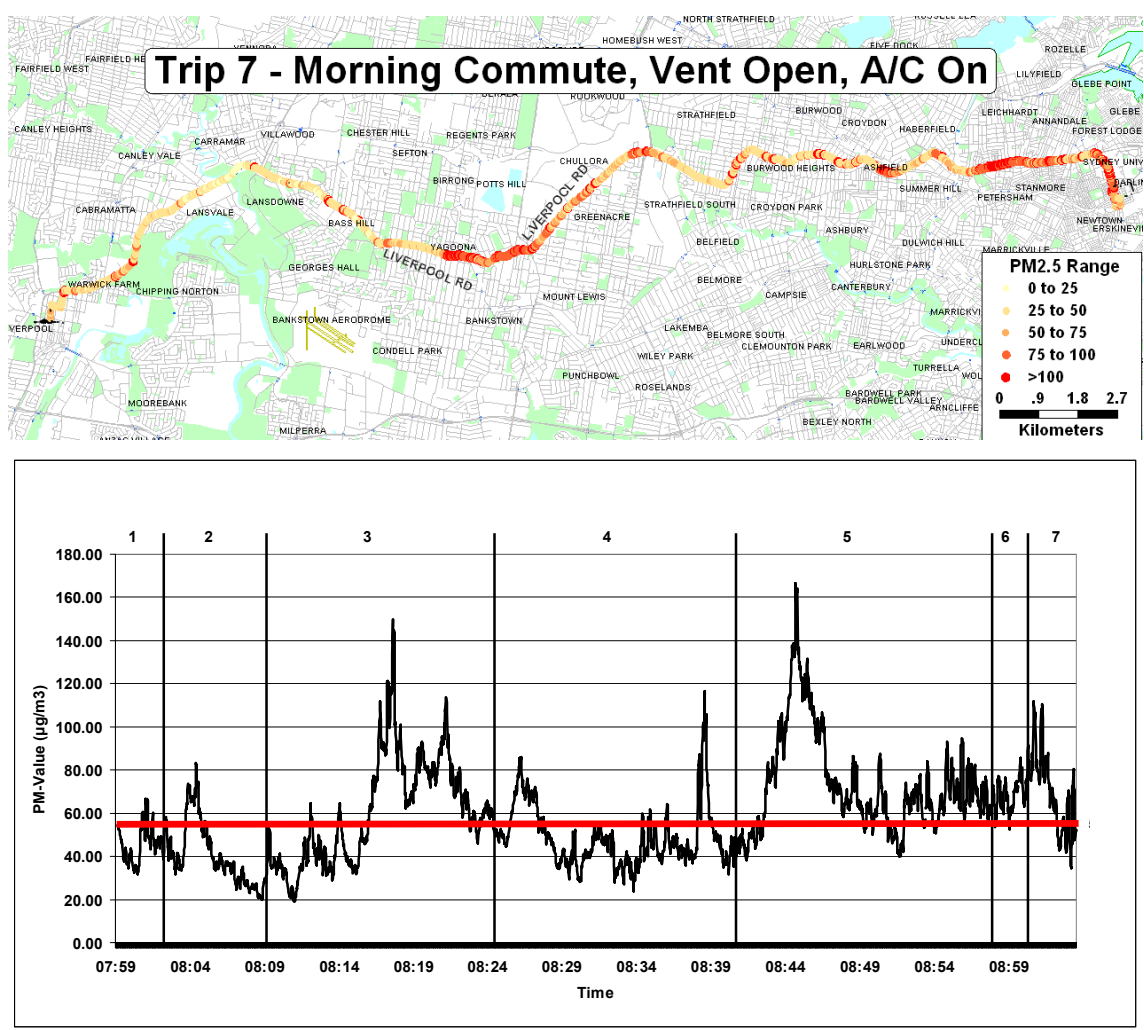

\begin{tabular}{|c|c|c|c|c|c|c|}
\hline Section & $\begin{array}{lr}\text { Average } & \text { Daily } \\
\text { Traffic } & \text { (RTA } \\
\text { traffic statistics) }\end{array}$ & $\begin{array}{l}\text { Average } \\
\left(\mu \mathrm{g} / \mathrm{m}^{3}\right)\end{array}$ & $\mathrm{PM}_{2.5}$ & $\begin{array}{l}\text { Average } \\
(\mathrm{km} / \mathrm{h})\end{array}$ & Speed & $\begin{array}{l}\text { No. of } \\
\text { Stops }\end{array}$ \\
\hline 1 & 8983 & 45.83 & & 13.6 & & 1 \\
\hline 2 & 51,740 & 40.44 & & 46.0 & & 2 \\
\hline 3 & 59,201 & 61.17 & & 34.5 & & 7 \\
\hline 4 & 35,454 & 46.33 & & 34.5 & & 4 \\
\hline 5 & 69,945 & 72.93 & & 17.2 & & 10 \\
\hline 6 & $\mathrm{n} / \mathrm{a}$ & 68.38 & & 7.0 & & 4 \\
\hline 7 & 4,000 & 70.79 & & 10.0 & & 4 \\
\hline TOTAL & ----- & 58.97 & & 27.1 & & 32 \\
\hline
\end{tabular}

Figure 3: Example GIS plot, time-series and summary statistics for a car trip.

The reasons for these hotspots are inconclusive based on the GIS plots alone. For instance, intuition suggests these could bee around intersections where the vehicle is stopped or in congested conditions and therefore more susceptible to 
fumes from surrounding vehicles. However, taking the example presented here, the speed at the three large spikes at 8:19 a.m., 8:39 a.m., and 8:44 a.m., was $52 \mathrm{~km} / \mathrm{h}, 44 \mathrm{~km} / \mathrm{h}$ and $12 \mathrm{~km} / \mathrm{h}$ respectively, suggesting (other than in the latter case) this is too simplistic an assertion. We have subsequently completed some runs in which we have also taken video footage to try to establish what exactly is going on at the time of these spikes. Based on this, it is quite apparent that specific vehicles are causing these problems, particularly trucks and buses and in some cases light-duty vans.

Another significant insight provided by this approach has been the impact of the in-vehicle environment on results. For the commuter trip illustrated previously, a number of runs were completed with different combinations of vent position (open/closed) and air-conditioning (on/off) as evidence as well as intuition suggests this has a major impact on particulates entering the vehicle [4]. While full details of the study are given in Greaves and Bertoia [8], a summary of results is provided in Table 1. Quite clearly, the opening of the vent has a dramatic effect, with concentrations increasing by three to four times depending on whether the air-conditioning was turned on or off. It is also notable from this that concentrations are substantially worse in the morning than afternoon by a factor of 30 to 50 percent depending on in-vehicle condition. This could reflect several interrelated factors including a specific time-of-day effect, the fact speeds are consistently lower in the mornings, a different mix of vehicles etc. Whatever, the specific reason(s), this is a finding corroborated by others [9].

Table 1: $\quad$ Summary trip statistics for 30 car trips from the western suburbs.

\begin{tabular}{|c|c|c|c|c|c|c|c|}
\hline \multirow[t]{2}{*}{ Condition } & \multirow{2}{*}{$\begin{array}{l}\mathrm{AM} \\
/ \mathrm{PM}\end{array}$} & \multirow{2}{*}{$\begin{array}{l}\text { Air-Con } \\
\text { /Vent }\end{array}$} & \multirow{2}{*}{$\begin{array}{l}\text { No. of } \\
\text { Trips }\end{array}$} & \multirow{2}{*}{$\begin{array}{l}\text { Mean } \\
\text { Speed } \\
\text { (kph) }\end{array}$} & \multicolumn{3}{|c|}{$\mathrm{PM}_{2.5}\left(\mu \mathrm{g} / \mathrm{m}^{3}\right)$} \\
\hline & & & & & Mean & SD & $\begin{array}{l}\text { Range of } \\
\text { Means }\end{array}$ \\
\hline $\mathrm{A}$ & $\mathrm{AM}$ & On/Closed & 6 & 26.9 & 20.6 & 8.1 & $13.9-28.0$ \\
\hline $\mathrm{B}$ & PM & On/Closed & 4 & 29.2 & 16.3 & 6.1 & $13.8-19.7$ \\
\hline $\mathrm{C}$ & $\mathrm{AM}$ & Off/Open & 5 & 26.9 & 85.6 & 45.6 & $65.0-114.8$ \\
\hline $\mathrm{D}$ & $\mathrm{PM}$ & Off/Open & 5 & 31.2 & 57.6 & 37.1 & 47.4-68.53 \\
\hline $\mathrm{E}$ & $\mathrm{AM}$ & On/Open & 5 & 27.5 & 60.4 & 30.6 & $41.6-73.2$ \\
\hline $\mathrm{F}$ & PM & On/Open & 5 & 35.5 & 46.0 & 52.0 & $26.3-56.3$ \\
\hline
\end{tabular}

\subsection{Bicycle trips}

The issue of exposure to air pollution while cycling is a particularly pertinent one because while it is considered a healthy activity, there are concerns that cyclists are both exposed to more $\mathrm{PM}_{2.5}$ than motorists and are more susceptible to it's impacts, because of greater lung exertion. The data we have collected thus far suggest that on busy, trafficked roads, cyclists may be exposed to lower levels than motorists (with their vents open), which is again a finding corroborated by others $[4,7]$.

As an illustration of this, Figure 4 presents an example of a one-hour cycling trip made from the university to a location in the Inner West of Sydney. The 
outward trip (Trip 1) was made during the evening rush hour and most of it is along a heavily trafficked route, while the return trip (Trip 2) was made along quieter streets. The average concentrations on the outward trip were $24 \mu \mathrm{g} / \mathrm{m}^{3}$ and the return $14 \mu \mathrm{g} / \mathrm{m}^{3}$. The hotspots for cyclists again appear to be largely attributed to the contribution of particular vehicles rather than traffic volumes per se. Cyclists also appear to be more susceptible to problems at intersections and specifically, whether they have to wait behind the cars or are able to get to the front of the queue - Sydney is slowly adopting pro-cycling measures at intersections but remains way behind much of Europe in this regard. An additional point that must be made and is exemplified by the return trip shown here is that simply by selecting quieter routes, these issues can be substantially mitigated.

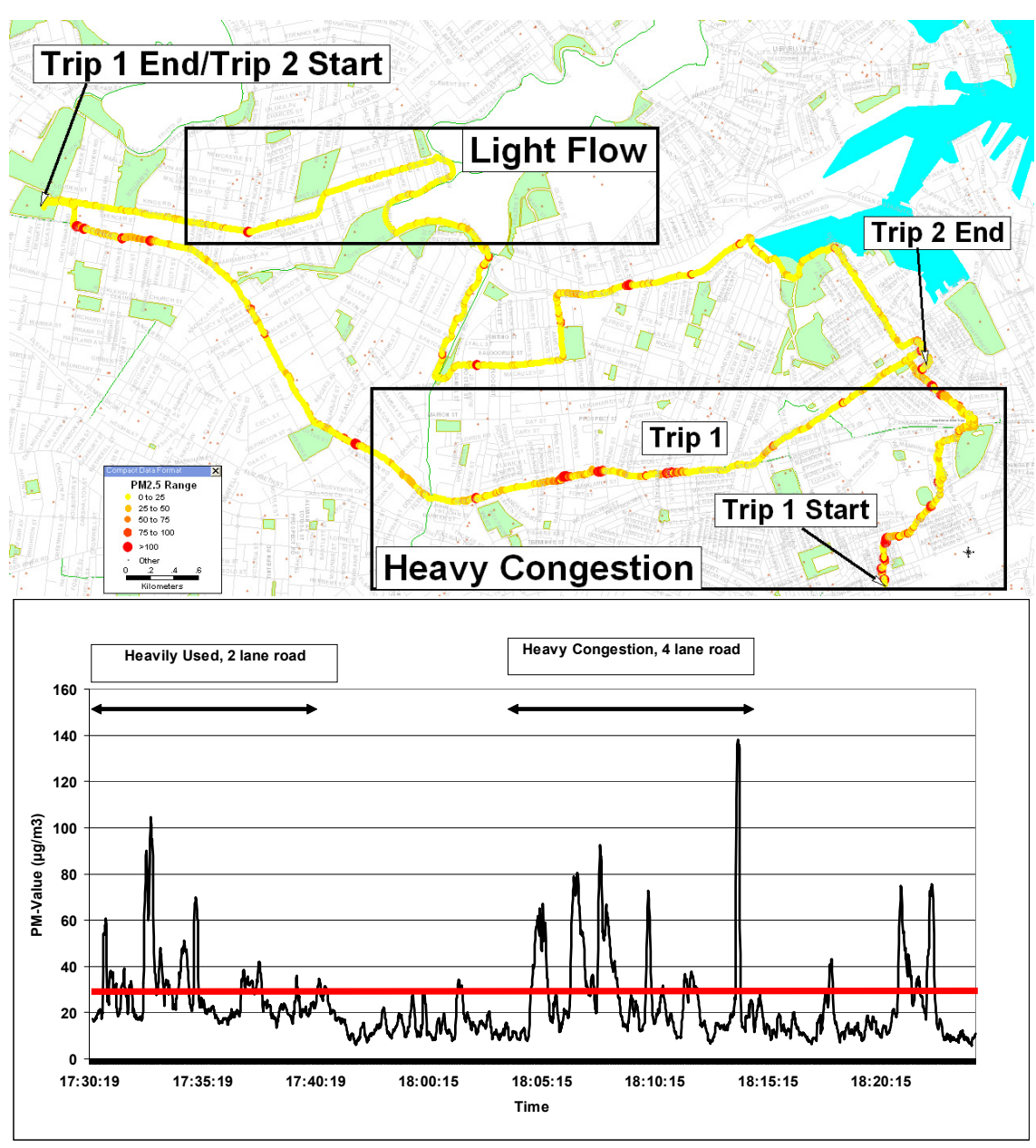

Figure 4: $\quad$ Example GIS plot for bicycle trips with time-series plot for trip 1. 


\subsection{Train trips}

The approach has also been used to collect $\mathrm{PM}_{2.5}$ data on train trips. The problems of GPS signal loss were naturally severe for trains, but this was overcome through our software processing by imputing position based on knowledge of the rail network, the location and time of the last known GPS points before and after the loss, and the rail timetable. Figure 5 shows the $\mathrm{PM}_{2.5}$ levels for one evening train trip from the university to Sydney's north shore. While the average concentrations over the trip were $38 \mu \mathrm{g} / \mathrm{m}^{3}$ this again hides significant intra-trip variability. In this case, the readings were significantly higher, when the train went into the tunnel under Central Sydney, here averaging $82 \mu \mathrm{g} / \mathrm{m}^{3}$. This finding is in line with existing evidence that suggests $\mathrm{PM}_{2.5}$ levels are significantly higher in underground railway locations [5].

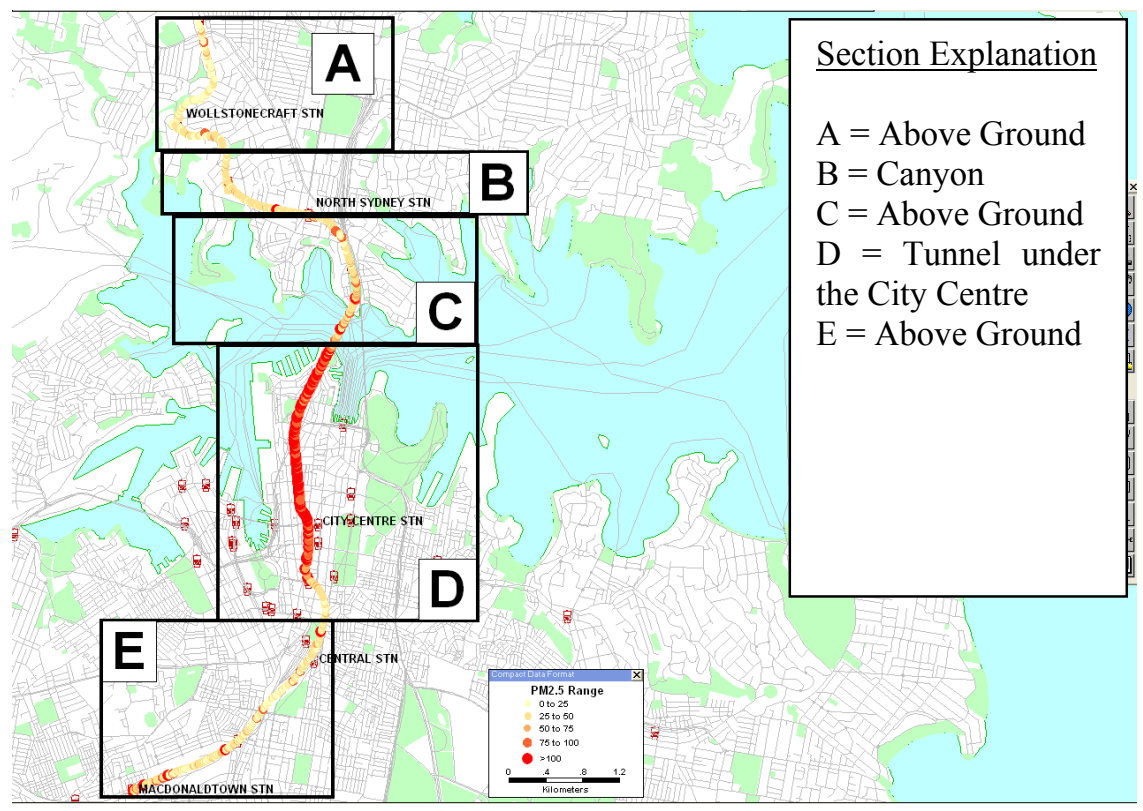

Figure 5: $\quad$ Example GIS plot for evening train trip.

The issue of elevated $\mathrm{PM}_{2.5}$ levels in trains raises an important point about whether we can simply rely on a size metric to indicate a potential hazard. In the case of train environments, intuition suggests the particles are substantially different in composition than roadway particles, comprising more ferrous-based matter. Even within roadway environments, it is probable particles comprise a variety of organic based compounds associated with the burning of fuel as well as road dust, tire fragments, pollens etc. Determining exactly what these particles comprise is something we are currently investigating by adapting the technology to also collect a gravimetric sample, which can later be weighed and analysed. 


\section{Conclusions}

Presented here is an intrinsically appealing method for gaining greater insight into the variability of (in this case, $\mathrm{PM}_{2.5}$ ) within transport microenvironments. The approach combines the capabilities of portable second-by-second pollution monitors with the automated spatial referencing capabilities of personal GPS devices with the caveat that (in the author's opinion) results should be used to indicate relative differences and identify areas for more detailed gravimetric analysis. The various examples presented highlighted not just the dangers of relying on average values to indicate concentrations, but that there were discernable hotspots, where levels were seriously elevated. In road environments, it appears too simplistic to attribute these elevated levels to traffic congestion per se, rather it appears that specific vehicles contribute disproportionately to the problem as has long been suspected [4]. This suspicion was corroborated through video evidence taken on some of the car trips, and we currently have plans to use a similar technique on bicycles.

This issue aside, there are certain tangible factors that impact the concentrations of $\mathrm{PM}_{2.5}$. Using simple regression analysis, for instance, the author found that in a car, 40 percent of the variability is simply explained by whether the vent is open or not [8]. Time-of-day emerges as the next most important factor (higher concentrations in the morning than afternoon), explaining an additional five percent, followed by air-conditioning (additional three percent), and speed (additional two percent). Current work is looking at refining the prediction by building in segment-specific attributes to try to explain some of the obvious variability shown in Figure 3. If this does not overcome the serious autocorrelation problems present within the data, the next stage will be to employ a time-series modelling approach.

As we continue to improve our understanding of what the precursors of $\mathrm{PM}_{2.5}$ are while travelling, it is also critical to appreciate there are other components to this story that need serious attention. First, to reiterate the point made in the previous section, there is a need to understand what exactly these particles comprise and assess their toxicity through laboratory analysis. Second, while the evidence presented here identifies discernible hotspots, the health impacts of repeated short bursts of exposure to elevated levels of $\mathrm{PM}_{2.5}$ have still to be scientifically established. This issue is currently a major one in Sydney, because of the large road tunnel network and heavy volumes of traffic that use them. Third, there is the need to tie this collection of detailed information in with the provision of accurate, real-time information to the public about local air quality problems, something that is currently being trialled in London. Finally, it is important to acknowledge while the current focus of particulate standards (in Australia at least) is migrating from $\mathrm{PM}_{10}$ to $\mathrm{PM}_{2.5}$, it is likely in the near future, that ultrafine particles may become the major issue because of their strong association with road traffic and greater potential health impacts. 


\section{References}

[1] Kappos, A.D., et al, (2004). Health Effects of Particles in Ambient Air. International Journal of Hygiene and Environmental Health, 207, 399-407.

[2] Michaels, R.A. and M.T. Kleinman (2000) Incidence and Apparent Health Significance of Brief Airborne Particle Excursions. Aerosol Science and Technology 32, 92-105.

[3] Riediker, Cascio, Griggs, Herbst, Bromberg, Neas, Williams and Devlin (2004). Particulate Matter Exposure in Cars Is Associated with Cardiovascular Effects in Healthy Young Men. American Journal of Respiratory and Critical Care Medicine, 169, 934-940.

[4] Taylor, D and M. Ferguson (1998) The Comparative Pollution Exposure of Road Users - a Summary. World Transport Policy and Practice, 4 (2), pp. 22-26.

[5] Adams, H.S., M.J. Nieuwenhuijsen and R.N. Colville (2001) "Determinants of Fine Particle $\left(\mathrm{PM}_{2.5}\right)$ Personal Exposure Levels in Transport Microenvironments, London, UK," Atmospheric Environment, 35, Issue 27, September, 2001, pp. 4557-4566.

[6] Gulliver, J. and D.J. Briggs (2004) Personal exposure to particulate air pollution in transport microenvironments. Atmospheric Environment, 38, pp. 1-8.

[7] Rank, J., J. Folke, and P.H. Jespersen (2001) Differences in cyclists and car drivers exposure to air pollution from traffic in the city of Copenhagen. The Science of the Total Environment, 279, 131-136.

[8] Greaves, S.P. and T. Bertoia (2006) Variability of Personal Exposure to Fine Particulates for Urban Commuters Inside an Automobile. CD-ROM Proceedings of the $85^{\text {th }}$ Annual Meeting of the Transportation Research Board, Washington DC, January, 2006.

[9] Alm, S., J. Jantunen and M. Vartianinen (1999) Urban commuter exposure to particle matter and carbon monoxide inside an automobile. Journal of Exposure Analysis and Environmental Epidemiology, 9, pp237-244.

[10] Weijers, E.P., A.Y. Khlystov, G.P.A. Kos, and J.W. Erisman (2004) Variability of particulate matter concentrations along roads and motorways determined by a moving measurement unit. Atmospheric Environment, 38, pp. 2993-3002.

[11] Stopher, P.R., S.P. Greaves, and C. Fitzgerald (2005) Developing and Deploying a New Wearable GPS Device for Transport Applications. $C D$ ROM Proceedings of the $28^{\text {th }}$ Australasian Transport Research Forum.

[12] Chang, L.T., Suh, H.H., Wolfson, J.M. et al. (2001). Laboratory and field evaluation of measurement methods for one-hour exposures to $\mathrm{O} 3, \mathrm{PM}_{2.5}$, and CO. Journal of the Air and Waste Management Association, 51, 14141422.

[13] Kim, J.Y., Magari, S.R., Herrick, R.F., Smith, T.J. \& Christiani, D.C. (2004). Comparison of Fine Particle Measurements From A Direct-Reading Instrument and a Gravimetric Sampling Method. Journal of Occupational and Environmental Hygiene, 1, 707-715. 